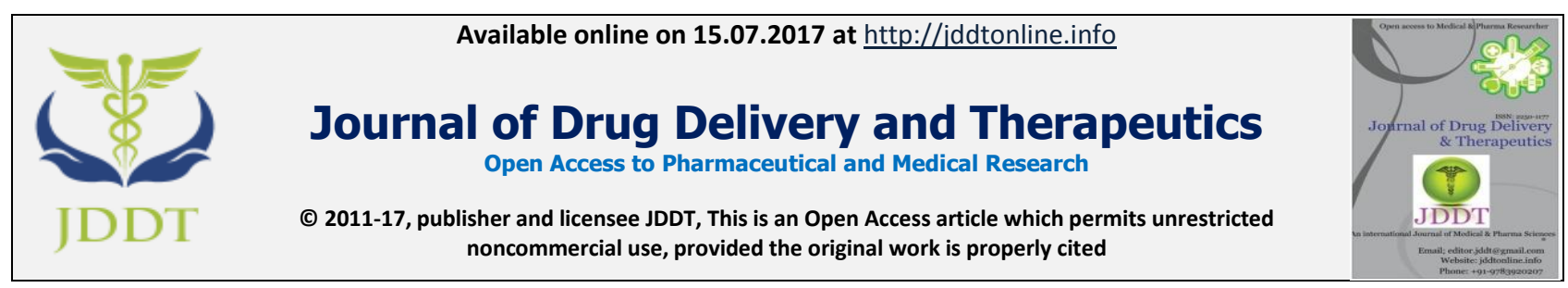

Open $\odot$ Access

Review Article

\title{
NOVEL TECHNOLOGY USED IN THE PREFORMULATION STUDY:
} A REVIEW

\author{
Md Shariq Ansari ${ }^{1}$, Dilip K Patel ${ }^{2 *}$, Roohi Kesharwani ${ }^{2}$, Dr. Vikas Kumar \\ ${ }^{1}$ Chandra sheikhar Singh College of Pharmacy, Koilaha, Kaushambi, U.P. INDIA \\ ${ }^{2}$ Department of Pharmaceutical Sciences, SHIATS, Allahabad, U.P., India
}

\section{ABSTRACT}

Preformulation is a study which deals which provides the framework for drug's combination with pharmaceutical ingredients in the fabrication of dosage form. Preformulation study is to develop the elegant dosage form by the establishing kinetic rate profile, compatibility with the other ingredients, establish physicochemical parameter and polymorphism of the new drug. Among these properties the preformulation also provide the information regarding degradation process, adverse condition relevant to the drug, bioavailability, pharmacokinetics, toxicity, drug stability, partition coefficient, dissolution rate, and polymorphic forms. Preformulation studies strengthen the scientific foundation of the guidance, provide regulatory relief and conserve resources in the drug development and evaluation process, improve public safety standards, enhance product quality, facilitate the implementation of new technologies. According to $\mathrm{ICH}$, all technical requirements for the application of drug approval were homonized in CTD format which are scientifically more elaborate by USFDA in QoS-QbR format. QbR is based on the principle of Quality by Design $(\mathrm{QbD})$ which increased efficiently in the FDA review process.

Keywords: Preformulation, Physiochemical properties, Polymorphism, Quality by design (QbD), ICH guideline.

Article Info: Received 07 June, 2017; Review Completed 12 July, 2017; Accepted 13 July, 2017; Available online 15 July, 2017

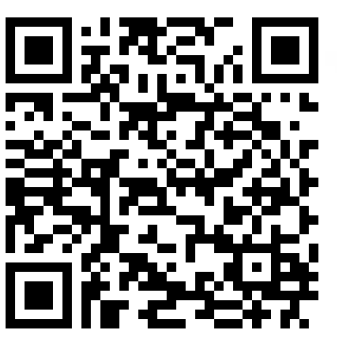

Cite this article as:

Ansari MS, Patel DK, Kesharwani R, Kumar V, Novel technology used in the preformulation study: a review, Journal of Drug Delivery and Therapeutics. 2017; 7(4):20-33

DOI: http://dx.doi.org/10.22270/jddt.v7i4.1487

*Address for Correspondence

Dilip K Patel, Department of Pharmaceutical Sciences, SHIATS, Allahabad, U.P., India

Email: dilippatel87mph@gmail.com

\section{INTRODUCTION}

Preformulation studies was established in 1950 \& early 1960. Almost all drugs are marketed as tablets, capsule or both. Prior to this development of major dosage form it is essential to investigate the physical \& chemical properties of the drug substance alone or combined with excipients are formulated in the suitable form that can be administered $^{1 .}$ Preformulation commences this all drugs shows sufficient pharmacologic promise in animal's models to warrant evaluation in man. These studies reflect on those physiochemical parameters of the new compound that would affect drug performance and development of efficacious dosage form ${ }^{2}$.

The first learning phase of the drug is known as preformulation. Preformulation is the interference of the new drug entity and formulation development. Preformulation involve the application of biopharmaceutical principles of the physicochemical property of the drug with the goal of designing effective drug delivery system. Preformulation studies are an important tool for early development in the both of API and drug products. The interaction of the drug 
component and excipients are used in the preformulation study. After the biological screening of the drug a formal preformulation should be started when a decision is made for further development of the compound in clinical trials. IND, NDA and ANDA guidelines issued by the US FDA and ICH recommended the preformulation studies. Preformulation investigation were designed to deliver all necessary data (especially physico-chemical, physico-mechanical and biopharmaceutical properties of the drug substances, excipients and packaging materials) which influenced the formulation design, method of manufacturing, pharmacokinetic/biopharmaceutical properties of the resulting product ${ }^{3}$. Sustained release, sustained action, controlled release, extended action, timed release, depot and repository dosage forms are the terms used for that drug which is designed to achieve a prolonged therapeutic effect by the continuously releasing medication over an extended period of the time after the administration of single dose. The term "sustained release" has been constantly used to describe that pharmaceutical dosage form formulated to retard the release of a therapeutic agent ${ }^{4}$. Preformulation study of the zidovudine derivatives were carried out by using Differential Scanning Calorimetry, Thermogravimetry, X-Ray Powder Diffractometry and Aqueous Stability studies. X-Ray Powder diffractometry data demonstrated that compound which has 2-4 crystalline and 5-6 were amorphous. Preformulation and stability of the biological fluid of retrocycline RC-101 is a potentially anti-HIV topical microbicide. RC-101 was stable at $\mathrm{pH}$ 3,4 and 7 at $25^{\circ} \mathrm{C}$ and $37^{\circ} \mathrm{C}^{3}$.

\section{NEED/IMPORTANCE OF DOSAGE FORM ${ }^{1}$}

$>$ To provide safe, effective \& convenient delivery of accurate drug.

$>$ To protect from destructive environment such as oxygen or humidity.

$>$ To protect from the gastric acid and effect after oral administration. Example: enteric coated tablet.

$>$ To suppress the odor and taste of the drug.

$>$ To provide solubility and stability for that liquid preparation which are unstable or insoluble. Example: suspension.

$>$ To provide rate controlled drug action. Example: sustained release and controlled release tablet such as aspirin.

\section{OBJECTIVE OF PREFORMULATION ${ }^{1}$}

$>$ To formulate or develop the elegant dosage forms.

$>$ It provides knowledgeable information for the formulator to design an optimum drug delivery system.

$>$ It is the first step before formulating or development of raw material into dosage form.

INVESTIGATION \& RESEARCH ON THE PREFORMULATION

\section{A. Bulk characterization}

$>$ Crystalllinity and polymorphism

$>$ Hygroscopicity

$>$ Fine particle characterization

ISSN: 2250-1177
Powder flow properties

Bulk density

\section{B. Solubility parameter}

$>$ Ionization constant- $\mathrm{pKa}$

$>\mathrm{pH}$ solubility profile

$>$ Common ion effect-Ksp

$>$ Thermal effect

$>$ Solubilization

$>$ Partition coefficient

$>$ Dissolution

\section{Stability parameter}

Stability in toxicology preparation

$>$ Solution stability

$>\mathrm{pH}$ stability

$>$ Bulk stability

$>$ Compatibility

\section{BULK CHARACTERIZATION}

Bulk characterization deals with the almost all solid for of drug. Bulk properties of the solid form, such as particle size, bulk density and surface morphology, flow ability and strength and strength of agglomeration can significantly impact downstream formulation process. Therefore, comprehensive characterization of all preformulation bulk lots of is necessary to avoid misleading prediction of stability or solubility 5 .

\section{1) Crystallinity and Polymorphism}

Crystallinity refers to the degree of structural order in a solid. Crystal habit and the internal structure of the drug can affect bulk and physicochemical properties. Habit is a description of outer appearance of crystal and the internal structure describe the molecular arrangement within the solid, changes in the internal structure usually after the crystal habit. Several examples of different habits of crystals are shown ${ }^{2}$

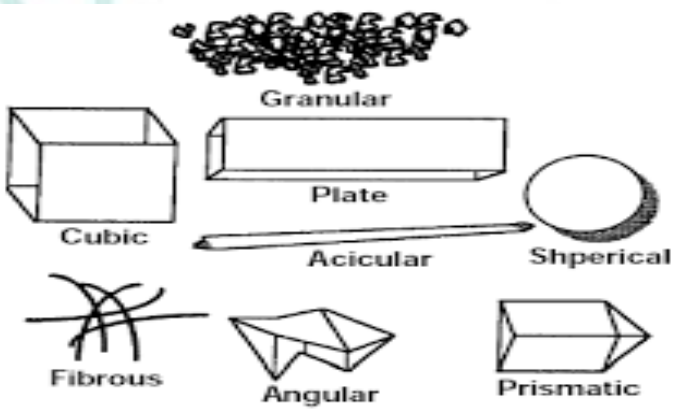

Figure 1: Differential habits of crystals ${ }^{1}$

Polymorphism is the ability of a compound to crystalline as more than one distinct crystalline species with different internal Latin. Many physiochemical properties vary with internal structure of solids e.g. melting point, density, hardness, crystal shape, optical property, solubility ${ }^{6}$. Polymorphisms are of two types:

Enantiotropic: enantiotropic polymorphisms can be reversely changed into another by varying temperature and pressure. E.g. sulphur, carbon, nitrogen and oxygen

Monotropic polymorphism: polymorph is unstable at all temperature and pressure. E.g. glyceryl stearate. 


\section{ANALYTICAL TECHNIQUE USED FOR CHARACTERIZATION OF SOLID:}

\section{Method}

Microscopy

$>$ Fusion method

$>$ Differential scanning Calorimetry (DSC)

$>$ Infrared spectroscopy

$>$ X-ray powder diffraction

$>$ Scanning electron microscopy

$>$ Thermo gravimetric analysis

\section{Material required per sample}

$1 \mathrm{mg}$

$1 \mathrm{mg}$

$2-5 \mathrm{mg}$

$2-20 \mathrm{mg}$

$500 \mathrm{mg}$

$2 \mathrm{mg}$

$10 \mathrm{mg}$

\section{a) Microscopy:}

Almost all substances that are transparent when examined under a microscope that has crossed polarizing filters are either isotropic or anisotropic. Amorphous solid and non-crystalline solid organic compound are isotropic materials, which have single refractive index. When the plain polarized filter passed these isotropic substances do not transmit light and appear black. Materials more than one refractive index is anisotropic and appears bright against the black polarized background. The interference of colors is depending upon the crystal thickness and their refractive indices. Anisotropic are either uniaxial or biaxial. To obtain or describe the complete crystal form a crystallographic axes are required. The polarizing microscope fitted with a hot stage is a useful instrument for investigating polymorphism, melting points, transition temperature and rates of transition at controlled heating rate ${ }^{2}$ For describing the characterization of crystallinty of the drug the microscopy is divided into two types are:

- Scanning Electron Microscopy (SEM)

- Transmission Electron microscopy (TEM)

SEM: SEM is used to visualize the surface of the drug molecule. In this microscopy the electron beam is passed from the electron gun which rapidly moves over the surface of the specimen which led to scan the surface of the drug.

TEM: TEM is used to photograph detail structure within the drug molecule. A total magnification is about 20 million times can be achieved and objects as small as $2 \mathrm{~nm}$ can be seen. TEM penetrate the surface of the drug and shows internal structure of the drug.

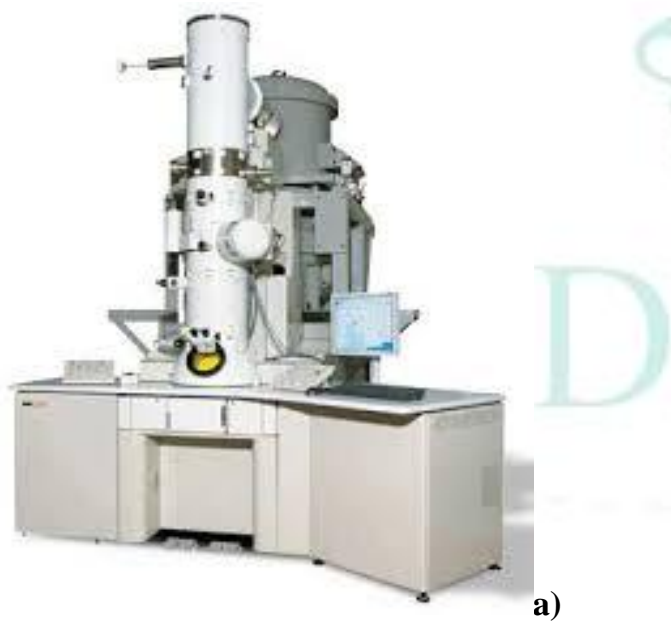

Figure 2: a) Scanning electron microscopy

\section{b) Fusion method (hot-melt method):}

In this fusion method, carrier is heated slightly above its melting point and the drug is incorporated into a matrix. Then the mixture is cooled with constant stirring. The dispersion may be cooled slowly to room temperature or rapidly in an ice bath ${ }^{7}$. The fusion method is also known as hot-melt method. This term can be used only when the starting material is crystalline in nature. When the dispersion is cooled the resultant product is pulverized and sieved. If the mixing of the components is performed by an extrusion process, then the method is known as the hot melt extrusion method ${ }^{8}$.

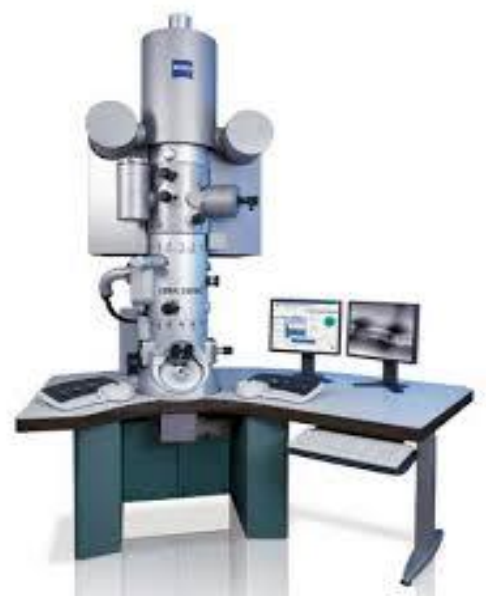

b)

\section{c) Differential Scanning Calorimetry (DSC/DTA):}

Differential Scanning Calorimetry (DSC) is one of the most widely used thermal analytical methods of analysis. The technique such as DSC (Differential Scanning Calorimetry) and DTA (differential Thermo Analysis) are based on the principal of measuring the changes in physical properties of a substance as a function of temperature when that substance is subjected to a controlled temperature program. DSC is defined as "A technique in which a difference in the heat flow (power) to the sample (pan) is monitored against time or temperature ${ }^{7}$. The plot is obtained from the DSC 
instrument is seen as a heating rate versus temperature or time. Differential Scanning Calorimetry has evolved from the technique of Differential Thermal Analysis (DTA) but does not account for the fundamental change in the working principle ${ }^{6}$. It includes some changes in thermocouple sensor's position and keeping the heat flux to the sample constant. DSC is also used to describe the physical and chemical property of the sample. DSC is classified into following types are:

- Heat flux DSC

- Power compensated DSC ${ }^{8}$

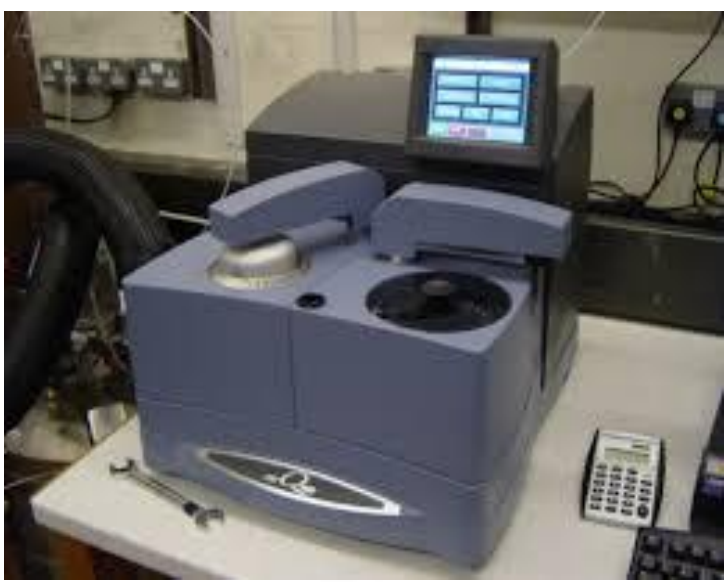

a)

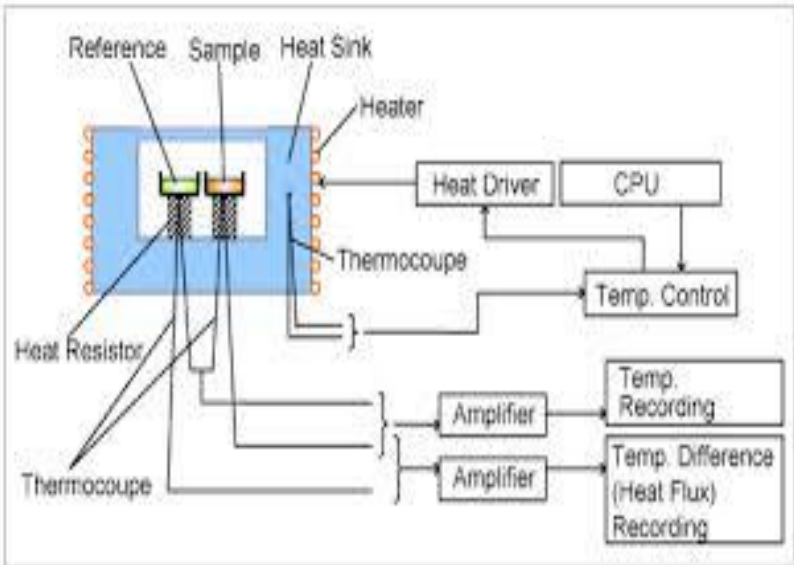

b)

Fig.3: a) Machine view of DSC b) Schematic view

\section{C) Infrared Spectroscopy:}

Infrared spectroscopy is the spectroscopy that deals with the infrared region of the electromagnetic spectrum that is light with a longer wavelength and lower frequency than visible light. It is based on the absorption spectroscopy. The method or technique of infrared spectroscopy uses an instrument called infrared spectrometer to produce infrared spectrum 9 .

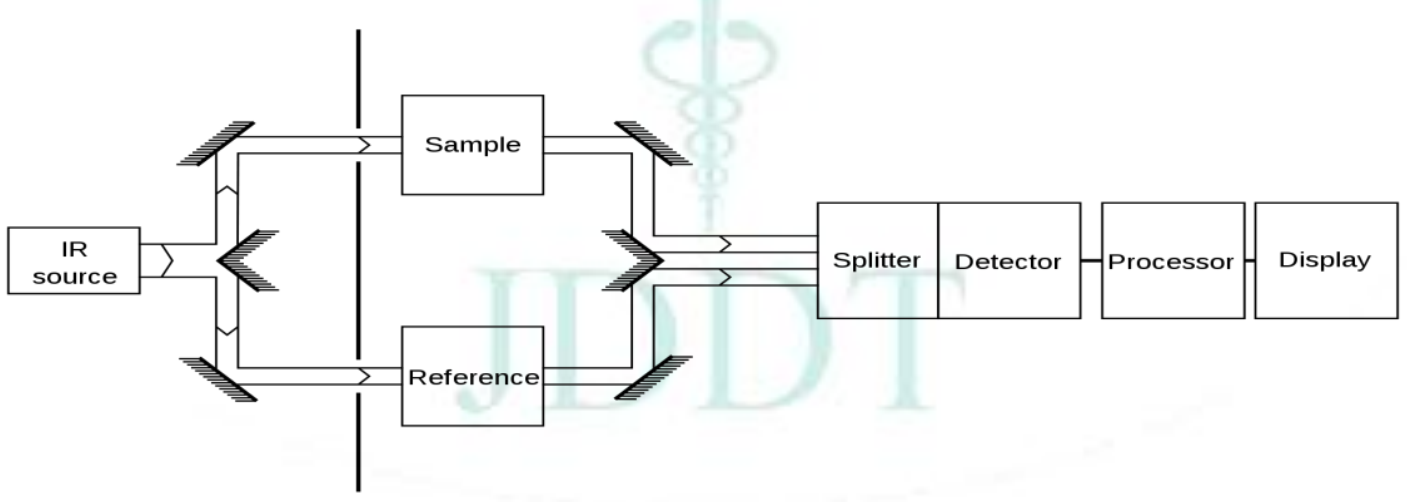

Fig.4: schematic view of IR Spectroscopy (Schematics of a two-beam absorption spectrometer. A beam of infrared light is produced, passed through an interferometer (not shown), and then split into two separate beams. One is passed through the sample, the other passed through a reference. The beams are both reflected back towards a detector, however first they pass through a splitter, which quickly alternates which of the two beams enters the detector. The two signals are then compared and a printout is obtained. This "two-beam" setup gives accurate spectra even if the intensity of the light source drifts over time.

\section{d) X-Ray Powder Diffraction (XRPD):}

XRPD was performed to observe the physical state of the solid dispersion and to evaluate any interaction between the drug carrier and adsorbent in solid dispersion. PAN analytical X-pert Pro V.1.6 with X-Pert Data Collector V2.1 software was used equipped with
$\mathrm{CuK} \alpha$ anode tube and difftactometer of radius $240 \mathrm{~mm}$. The XRD scan was performed using BB004 flat stage. The powdered sample was placed in a plastic sample holder of 1inch square. Data were collected at $45 \mathrm{KV}$ and $40 \mathrm{~mA}$. Samples were scanned from 0-40.20 at a stop size of 0.0084 and scan rate of $1.00 \% \mathrm{~min}^{1}$. 

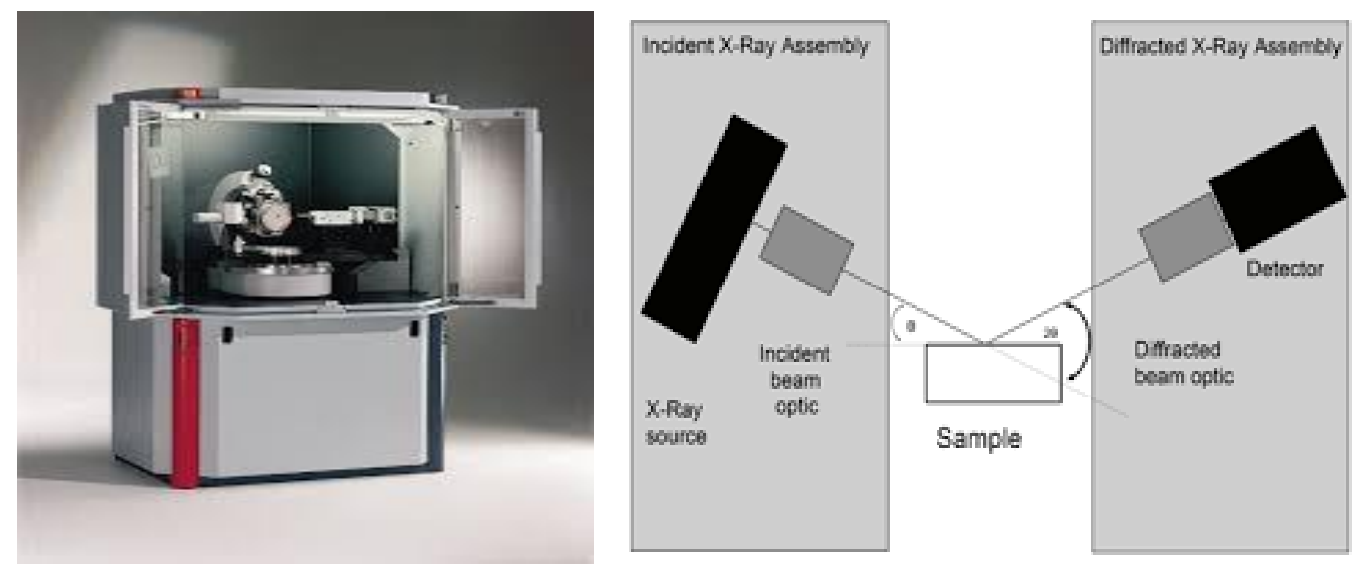

Fig.5: X-Ray diffraction technique

\section{e) Scanning Electron Microscopy (SEM):}

SEM is used to visualize the surface of the drug molecule. In this microscopy the electron beam is passed from the electron gun which rapidly moves over the surface of the specimen. This causes the release of shower of secondary electron and other type of variation which lead to see the scan the surface of the drug. The surface characteristics of the drug carrier, adsorbent and solid dispersion were suited using a scanning electron microscope equipped with JSM 6100. It provides the digital picture of the sample ${ }^{11}$. Double sided adhesive tape was used to fix the sample onto a brass stub, which was coated in a sputter coater under vacuum. The SEM pictures for all samples were taken under a magnification of $10 \mathrm{X}^{12 .}$

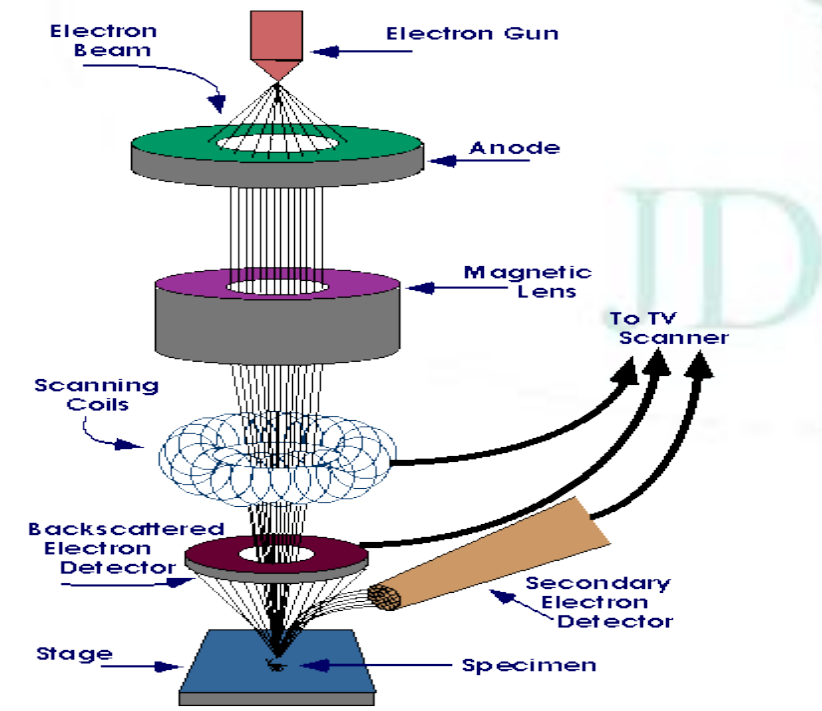

Fig.6: Scanning electron microscopy (Purdue University, West Lafayette, IN 47907, (765) 494-4600 (C) 2014 Purdue University)

\section{f) Thermogravimetric Analysis:}

Thermo gravimetric analysis or thermal gravimetric analysis (TGA) is a method of thermal analysis in which changes in physical and chemical properties of material are measured ${ }^{2}$. As function of increasing temperature or as a function of physical phenomena, such as second order phase transitions including vaporization, sublimation, absorption, and adsorption and desorption.
TGA also provide chemical phenomena including chemisorption, desolation, decomposition and solid-gas reaction. It is useful technique for the study of polymeric materials, including thermoplastic, thermo sets, composites, plastic films, fibers, coating and paints 13 .

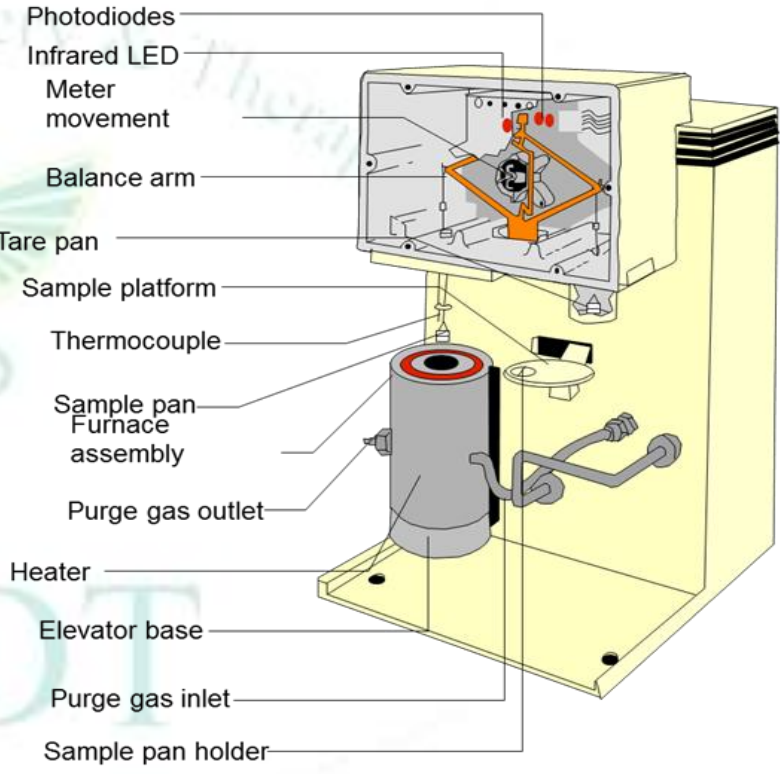

Figure 7: Q50 TGA Instrument Scheme ( Kessler, Michael. "Lab 10: TGA" Laboratory Manual. Mat E 453. Iowa State University. 13 November 2012)

\section{2) Hysgroscopicity}

A substance which absorbs sufficient moisture from the atmosphere is called hygroscopic. Many drug substances, particularly water-soluble salt forms have tendency to absorb atmospheric moisture ${ }^{14}$ Adsorption and equilibrium moisture content can depend upon the atmospheric humidity, temperature, surface area, exposure, and the mechanism or moisture uptake, as described by Van Campen. Some materials adsorb sufficient water to dissolve completely, as is observed with sodium chloride on a humid climate. Other hygroscopic substances adsorb water because of hydrate formation ${ }^{2}$.

To test for hygroscopicity bulk samples of drug are placed in open containers with a thin powder bed to assure maximum atmospheric exposure. These samples 
are then exposed to a range of controlled relative humidity environments prepared with saturated aqueous salt solution. The moisture uptake by the sample can be monitored at the representative of handling ( 0 to $24 \mathrm{hrs} 0$ and storage ( 0 to 12 weeks) ${ }^{15}$. Analytic methods for monitoring the moisture level by Gravimetric Analysis, Thermo gravimetric analysis, Karl Fischer titration, or gas chromatography.

\section{3) Fine Particle Characterization}

- Bulk flow, formulation homogeneity and surface area controlled processes such as dissolution and chemical reactivity are directly affected by size, shape, and surface morphology of the drug particle. Before the preformulation each new drug should be tested with the smallest particle size as is practical facilitate preparation of homogeneous samples and maximize the drug's surface area for interactions 11 .

- To determine the shape and size of the particle a light microscope with a calibrated grid usually provides adequate size and shape characterization for drug particles. Sampling and preparation of microscopic slide must be performed carefully to obtain representative dispersion ${ }^{16}$ The use of photomicrographs and a hemacytometer slide, as well as other sizing techniques may take this task slight less strenuous. In conjunction with light microscopy, stream containing devices such as Coulter counter and HIAC counter often provide a convenient method for characterizing the size distribution of a compound. Sample are prepared for analysis by the Coulter counter by dispersing the material in a conducting medium such as isotonic saline with the aid of ultrasound and a few drops of surfactant $^{12 .}$ A known volume of the suspension is then drowning into a tube through a small aperture across which a voltage is applied. As each particle passes through the hole counted the size acc. To the resistance generated by displacing that particle's volume of conducting medium.

- Sieve sample are used primarily for large samples of relatively large particles ( 100 microns $) 17$.

- Computer interfacing of image analysis techniques offers the greatest promise for the particle size analysis.

- A more precise method for measurement of surface area is made by Brunauer Emmett and Teller (BET) by adsorption and desorption of nitrogen and calculating the value we can determine the surface area of particle.

- Surface morphology may be observed by scanning electron microscopy (SEM) which serves to confirm qualitatively a physical observation related to surface area. Most modern SEM instruments also provide energy dispersive X-Ray spectroscopy analysis of surface metal ions, which may prove beneficial in deciphering an instability or incompatibility problem

- The laser diffraction has become preferred choice laser diffraction, alternative referred to as low angle laser light scattering (LALLS) can be used for the nondestructive analysis of wet or dry samples, with particle size range 0.02 to 2000 microns. Laser diffraction based particle size analysis relies on the fact that particles passing through a laser beam will scatter light at an angle that is directly related to their size. As particle size decreases the observed scattering angle increases logarithmically. E.g.The Master sizer 2000: a mastersizer has a fully optimized optical design which allows particles in the range of 0.02-2000 microns ${ }^{18 .}$

- Instrument for laser diffraction: LA-960, S2-100, PSA300/ CAMSIZER, VIEWSIZER 3000. ${ }^{19}$

\section{4) Powder Flow Characteristic}

Pharmaceutical powders may be broadly classified as free flowing or cohesive (non-free flowing). Most flow properties are significantly affected by changes in particle size, density, shape, electrostatic charge and adsorbed moisture which may arise from processing or formulation.

\section{Techniques:}

- FT4 Powder Rheometer: The FT4 Powder rheometer was originally designed to characterize the rheology or flow properties of powder. This remains a primary function today, but the instrument, accessories and methodologies have been continuously developed to the point where FT4 is now considered a universal tester ${ }^{20}$.

- 1ml Shear Cell: The freeman technology $1 \mathrm{ml}$ hear cell allows very small powder samples to be automatically tested, minimizing the consumption of scare and valuable material.

- Angle of Repose: Angle of repose has been used in the several branches of science to characterize the flow properties of solids. Angle of repose is a characteristic related to inter particulate friction or resistance to movement between particles. Experimental difficulties arise as a result of segregation of material and consolidation or aeration of the powder as the cone is formed. Despite its difficulties the method continues to be used in the pharmaceutical industry. The angle of repose is the three dimensional angle (relative to the horizontal base) assumed by a cone-like pile of material 21 . 
Table.1: For Angle of repose ${ }^{2}$

\begin{tabular}{|l|l|}
\hline Flow Property & Angle of Repose(degrees) \\
\hline Excellent & $25-30$ \\
\hline Good & $31-35$ \\
\hline Fair-aid not needed & $36-40$ \\
\hline Passable-may hang up & $41-45$ \\
\hline Poor-must agitate, vibrate & $46-55$ \\
\hline Very poor & $56-65$ \\
\hline Very, very poor & $>66$ \\
\hline
\end{tabular}

To calculate angle of repose following formula is used.

$$
\tan \emptyset=\text { height/base }
$$

- Compressibility index and Hausner's ratio: In recent years the compressibility index and the closely related Hausner's ratio have become the simple, fast, and popular methods of predicting powder flow characteristics. The compressibility index has been proposed as an indirect measure of bulk density, size and shape, surface area, moisture content, and cohesiveness of materials influence the observed compressibility index ${ }^{18}$. The compressibility index and the Hausner's ratio are determined by measuring both the bulk volume and the tapped volume of powder.

- The compressibility index and the Hausner's ratio may be calculated using measured value for bulk density and tapped density as follows:

Compressibility Index =

$$
\begin{array}{r}
\frac{\text { tapped density-bullk density }}{\text { tapped density }} * 100 \\
\text { Hausner's ratio }=\frac{\text { tapped density }}{\text { bulk density }}
\end{array}
$$

Table 2: Scale of flow ability

\begin{tabular}{|l|l|l|}
\hline Compressibility index $\mathbf{( 5 \% )}$ & Flow character & Hausner's ratio \\
\hline $\mathbf{1 0}$ & Excellent & $1.00-1.11$ \\
\hline $\mathbf{1 1 - 1 5}$ & Good & $1.12-1.18$ \\
\hline $\mathbf{1 6 - 2 0}$ & Fair & $1.19-1.25$ \\
\hline $\mathbf{2 1 - 2 5}$ & Passable & $1.26-1.34$ \\
\hline $\mathbf{2 6 - 3 1}$ & Poor & $1.35-1.45$ \\
\hline $\mathbf{3 2 - 3 7}$ & Very poor & $1.46-1.59$ \\
\hline $\mathbf{3 3 8}$ & Very, very poor & $>1.60$ \\
\hline
\end{tabular}

- Flow through an orifice: The flow rate of material is depending on many factors, some of which are particle-related and some related to the process. Monitoring the rate of flow of material through an orifice has been proposed as a better measure of powder flow ability. Changes in flow rate as the container empties can also be observed. The flow rate through an orifice $s$ generally measured as the mass per time flowing from any of a number of types of containers (cylinders, Funnel, hoppers). Measurement of the flow rate can be discrete increments or continuous 22 .

\section{5) Bulk Density}

Bulk density of a compound varies substantially with the method of crystallization, milling, or formulation. Once a density problem is identified, it is often easily corrected by milling, slugging, or formulation ${ }^{23}$. Bulk density is of great importance when one considers the size of high dose capsule product or the homogeneity of a low dose formulation in which there are large differences in drug and excipient densities. The bulk density of a powder is the ratio of the mass of an untapped powder sample and its volume. Including the contribution of the interparticulate void volume. Hence, the bulk density of powder particles and the spatial arrangement of particles in the powder bed ${ }^{2}$.

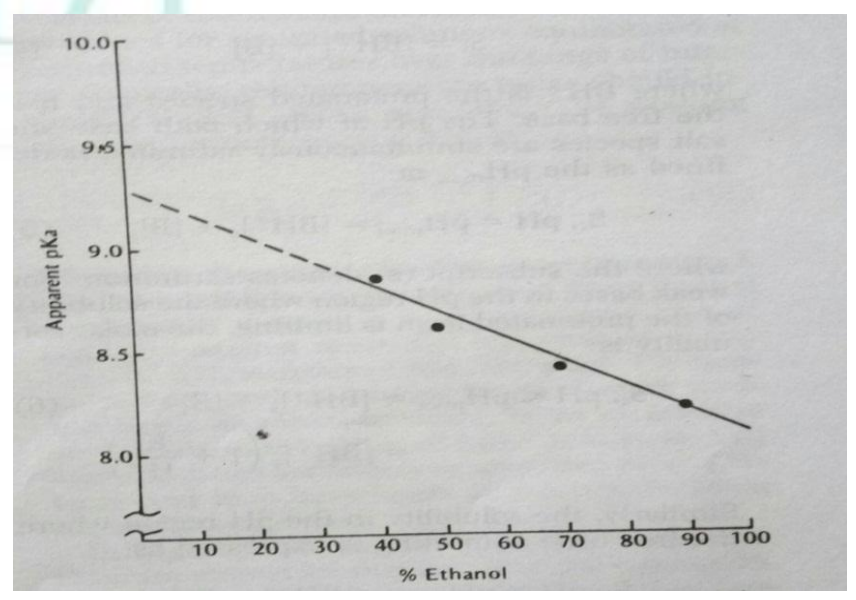

Figure 8: The pKa determination for an organic amine drug candidate whose un-ionized form is exceedingly insoluble in water ${ }^{2}$

\section{- Measurement in graduated cylinder}

Apparent density is determined by pouring perceived (40- mesh) bulk drug into a graduated cylinder via a 
large funnel and measuring the volume and weight "as is" 24 .

\section{- Measurement in a volumeter}

The apparatus consist of top funnel fitted with a $1.0 \mathrm{~mm}$ containing four glass baffle plates over which the powder slides and bounces as it passes. At the bottom of the baffle box is a funnel that collects the powder and allows it to pour into a cup mounted directly below it. The cup they be cylindrical $r$ cubical ${ }^{25}$.

\section{- Measurement in vessles}

The apparatus consist of a $100 \mathrm{ml}$ cylindrical vessel of stainless steel $52 \mathrm{~mm}$ long and $54 \mathrm{~mm}$ wide.

Marketed drug: Amoxicillin trihydrate.

\section{Solubility analysis:}

Preformulation solubility studies focus on drug solvent system that could occur during the delivery candidate, for example a drug for oral administration should be examined for solubility in media having isotonic chloride ion concentration and acidic $\mathrm{pH} 26$. Preformulation solubility studies usually includes determination of pka, temperature dependence, $\mathrm{pH}$ solubility profile, solubility products solubilization mechanisms and rate of dissolution analytical method that are particularly useful for solubility measurement including HPLC, UV, Spectroscopy, fluorescence spectroscopy and gas chromatography. For most drug reverse phase HPLC offer an efficient and accurate means of collecting solubility data. Solubility and dissolution experiment should have all factor defined, including $\mathrm{pH}$, temp, ionic strength and buffer concentration $^{2}$

\section{Constant (PKA Determination) Ionization}

Determination of the dissociation constant for a drug capable of ionization within a $\mathrm{pH}$ range of the 1 to 10 is imp. Since solubility and consequently absorption can be altered by orders of magnitude with changing $\mathrm{pH}$. The Henderson-hasselbalch equation provides an estimate of the ionized and un-ionized drug conc. at a particular $\mathrm{pH}$ 27 .

\section{For acidic compound}

$\mathrm{pH}=\mathrm{pKa}+\log \frac{\text { ionized } d r u g}{\text { unionized } d r u g}$

\section{For basic compound}

$\mathrm{pH}=\mathrm{pKa}+\log \frac{\text { unionized drug }}{\text { ionized drug }}$

For a weekly acidic drug with $\mathrm{pKa}$ value greater than 3 , the un-ionized form is present within the acidic content of the stomach, but the ionized drug is predominately in the neutral media of the intestine for basic drug such as erythro0mycin and papaverine, (pKa 8 to 9), the ionized form is predominant in both the stomach and intestine. A pKa values can be determined by a variety of analytic methods. Buffer, temp., ionic strength and cosolvent affect the pKa value ${ }^{28}$.

\section{Method of determination of dissociation constant:}

\section{a) High Performace Liquid Chromatography (HPLC):}

HPLC is valuable technique for this separation of weak acids and bases . a general equation which relates the observed retention factor to the $\mathrm{PH}$ of the mobile phase the dissociation constants and the retention factors of the different ionic species has been used to determine dissociation constant of polyprotic weak acid and base

\section{b) Hyper Rayleigh scattering:}

Hyper-Rayleigh scattering (HRS) is second harmonic light scattering mediated by the molecular by the first hyperpolarizability and HRS is widely used to measure technique used to obtain the dissociation constant of weak organic acid in protic solvent ${ }^{30}$. The degree of dissociation of the acid can be varied by altering the initial conc. of the acid solution. HRS technique is based on a hoo-photon scattering process and powerful IR lasers.

\section{c) Calorimetry:}

All Calorimetry method work by the same principle a physical or chemical process takes place in a sample and amount of heat evolved is measured. For the measurement of $\mathrm{pKa}$ values, in isothermal titration Calorimetry (ITC) a regular acid-base titration is carried out inside the calorimeter while the energy required keeping the temp. constant is measured ${ }^{31 .}$

\section{d) U V Visible Spectroscopy:}

The principle of UV-visible spectroscopy is the absorption of electromagnetic radiation from the 200800 range and the following excitation to higher energy states 32,3. UV-visible spectrophotometry handle compound with lower solubility and lower sample concentration. There are various UV methods such as simultaneous method, microliter plate method of multi wavelength spectroscopic method, second derivate method orthogonal method.

\section{e) Density Functional Theory (Dfi) Method:}

The density functional theory is the computerized method. DFI is nowadays one of the most popular methods for calculating $\mathrm{pKa}$ values. The $\mathrm{pKa}$ values where calculated with the jaguar $\mathrm{pKa}$ prediction modules using the thermodynamic cycle and following equation 33. Where $\mathrm{D}$ is the free energy changed

$$
\text { pKa }=1 / 2-3 \text { RT }^{*} \mathrm{D}
$$

\section{f) Isohydric Solution Principle:}

This method is very sensitive method, useful for weak acid characterized by low pKa values. We can test the effect of contamination of weak acid or its salt by a strong acid or base or carbonate. The pKa determine by isohydric principle method by following equation.

$$
\mathrm{C}=\mathrm{C}+\mathrm{C}^{2} \cdot 10^{\mathrm{PK} 1 \mathrm{~T}}
$$

\section{g) Solvaton Method:}

In this method dissociation constant measure by calculating the Gibbs energy change for the deprotonating in the gas phase and then using the 
salvation energies of the molecules, anion and the proton to estimate the Gibbs free energy of salvation ${ }^{34}$.

\section{h) Thermal Lensing Spectroscopy:}

Sung Ho Kim et al measure dissociation constant of thymol blue by using a portable Diode-laser/ fiber-optic thermal lensing spectroscopy, which consisted of a visible diode laser, a photodiode and an optical fiber ${ }^{35}$.

\section{i) Flourimetric Method:}

Flourimetry is a relatively fast and accurate means of determining the dissociation constant of sparingly soluble aryl amines and hydroxyl aromatic compound ${ }^{36}$.

\section{j) Flourescence Polarization Method:}

Linda prystay determine equilibrium dissociation constant of peptides size range from a 7 - mer at about $1,400 \mathrm{Da}$ (dermorphin) to a 22- mer at about 3,200 Da $(3,2000)$ by using fluorescence polarization saturation curve data 37 .

\section{k) Mass Pectroscopy:}

The chromatography together with mass spectroscopy method allowed for the quick determination constant and mainly applicable for complex mixture ${ }^{38}$.

\section{l) Surface Plasama Resonance:}

Surface plasma resonance (SPR) is generally accepted for the investigation of binding kinetics and binding strengths. SPR is most frequently used for studying bimolecular interaction. The principle of SPR measurement is relatively simple a "bait" ligand is immobilized on the gold surface of the gold surface of the SPR chip ${ }^{6,39}$.

\section{pH Solubility Profile}

The solubility of an acidic or basic drug depends on the $\mathrm{pKa}$ the ionizing functional group and the un-ionized form. St , is equal to the following summation

$$
\mathrm{St}=[\mathrm{BH}+]+[\mathrm{B}]
$$

Where $\mathrm{BH}+$ is the protonated species and $\mathrm{B}$ is the free base. The $\mathrm{PH}$ at which both base and salt species are simultaneously is defined as the $\mathrm{pH}$ max or.

$$
\mathrm{St}, \mathrm{pH}=\mathrm{pH} \max =[\mathrm{BH}+] \mathrm{s}+[\mathrm{B}] \mathrm{s}
$$

Where the subscript is denotes saturation. For weak bases in the $\mathrm{pH}$ region where the solubility of the protonated form is limiting, the molar solubility is

$$
\text { St, } \mathrm{pH}-\mathrm{pH} \max =\left[\mathrm{BH}^{+}\right] \mathrm{s}[\mathrm{B}] \mathrm{s}=\left[\mathrm{BH}^{+}\right]\left(1+\frac{K a}{H+}\right)
$$

Similarly, the solubility in the $\mathrm{pH}$ region where the free base is limiting is expressed as.

$$
\mathrm{PH} \max =\mathrm{pKa}+\mathrm{LOG}[\mathrm{B}] \mathrm{s}
$$

It therefore follows the $\mathrm{pH}$ max is defined as.

$$
\mathrm{pH}_{\max }=\mathrm{pKa}+\log \frac{[B] s}{[B H+] s}
$$

At a solution $\mathrm{pH}$ equivalent to $\mathrm{PH}$ max, both the free base and salt with can exist simultaneously in equilibrium with a saturated solution. The $\mathrm{PH} \max$ is verified by sampling precipitated drug from the equilibrated solution and confirming the presence of both drugs is the solubility-limiting species in solution, the concentration of the paired counter ion is usually the solubility determining factor ${ }^{40}$. A particularly useful by Kramer and Flynn for organic hydrochlorides $\mathrm{PH}$ solubility profile dependence on solvent composition. While most of this discussion as focused on solubility product limitations of basic compound. The $\mathrm{PH}$ solubility profile for doxycycline (pKa 3.4) reported by Bogardus and backwoods illustrates a common ion effect for an amine hydrochlorides salt ${ }^{2}$.

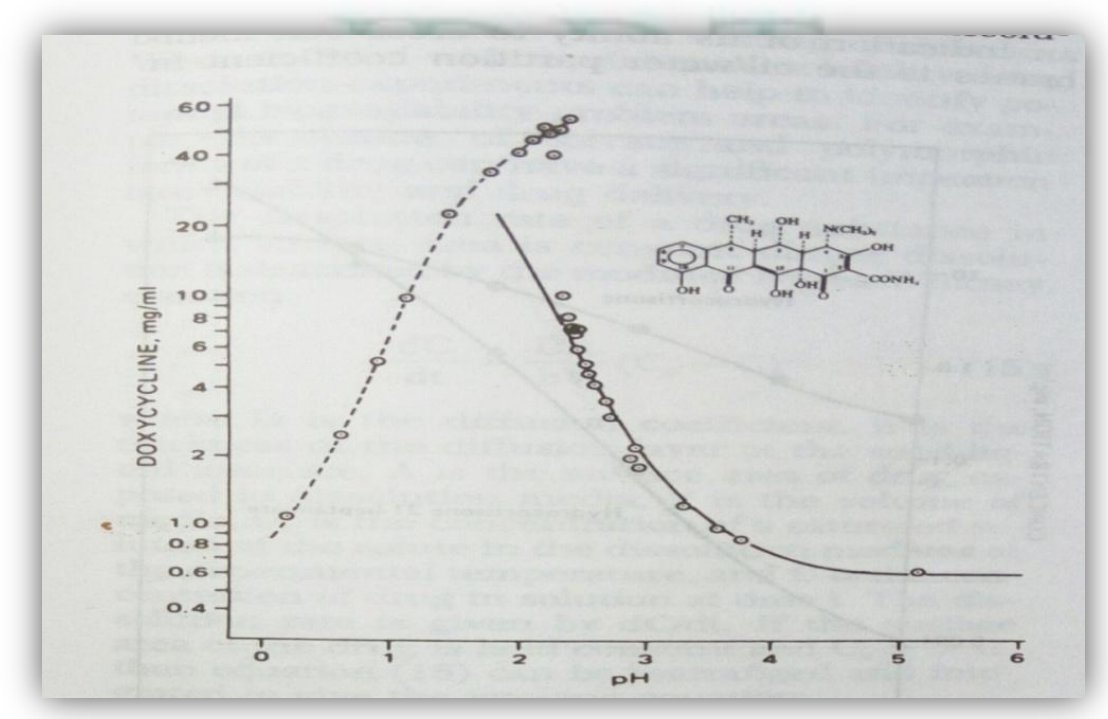

Figure 9: The $\mathrm{pH}$ solubility profile for doxycycline in aqueous hydrochloric acid at $25^{\circ} \mathrm{C}$. At $\mathrm{pH}=2.16$, both doxycycline monohydrate and doxycycline hydrochloride dehydrate were in equilibrium with solution. (From Lachman Leon, Lieberman Herbert A. and Kanig Joseph L. "The theory and pharmaceutical of industrial pharmacy" third edition, page no. 187)

\section{Common Ion Effect}

A common ion significantly reduces the solubility of a slightly soluble electrolyte. The common ion effect suppresser the ionization $f$ a weak acid by adding $f$ an ion that is a product of the equilibrium. The selling out result from the removal of water molecules as solvent 
owing to the completing hydration of other ions. The reverse process salting in cries with larger anions. E.g. benzoate, salivate which open the water structure. These hydro topics increase the solubility of properly water soluble compounds such as diazepam.

\section{Thermal Effect}

The heat of solution, represent the heat released or absorbed when a mole $\mathrm{f}$ solute $\mathrm{s}$ dissolved in large quantity of solvent, most commonly, the solution process is endothermic, or is profile is positive and thus increasing the solution temp. Increase the drug solubility. The working equation for determining $\mathrm{Hs}$ is:

$$
\mathrm{S}=\frac{-\Delta H s}{R}\left(\frac{1}{T}\right)+C
$$

Where, $\mathrm{S}$ is the molar solubility at temperature $\mathrm{T}$ and $\mathrm{R}$ is gas constant 2,41 .

The change in temperature produces changes in solubility.

\section{Solbilization}

For drug candidates with either poor water solubility or insufficient solubility for projected solution dosage forms preformulation studies should include limited experiments to identify possible mechanism for solubilization ${ }^{[2]}$. The solubility of poorly soluble nonelectrolytes can often be improved by orders of magnitude with suitable cosolvents such as ethanol, propylene, glycol, and glycerin. The extent of solubilization due to the chemical structure of the drug. That is the more nonpolar the solute, the greater is the solubilization achieved by cosolvent addition 42 .

\section{NOVEL TECHNIQUES}

\section{1) Hot-melt method (fusion method):}

The main advantage of this method is direct melting method is its simplicity and economy. The melting or fusion method was first proposed by sekiguchi and obi to prepare fast release solid dispersion dosage forms. In this the physical mixture of a drug and water soluble carrier are heated directly until the two melts. The melted mixture cooled and solidified rapidly and the final solids mass, is then crushed, pulverized and sieved which can sieve which can be compressed into tablets with the help of tableting agents 43 .

\section{2) Solvent evaporation method:}

Tachibana and nakamura were the first to dissolve both the drug and the carrier un a common solvent and then evaporate the solvent under vacuum to produce a solid solution. This enable them to produce ac solid solution of the highly lipophilic - carotene in the highly water soluble carrier providone ${ }^{44}$.

\section{3) Hot-Melt Extrusion:}

Hot melt extrusion is essentially the same as the fusion method except that intense mixing of the components is induced by the extruder 45 .

\section{4) Nanosuspension}

Nanosuspension technology has been developed as a promising candidate for efficient delivery of hydrophobic drugs. This technology is applied to poorly soluble drug that are insoluble in both water and oils. A pharmaceutical nanosuspension is a biphasic system consisting of nano sized drug particles stabilized by surfactants for either oral and topical use of parenteral and pulmonary administration. The particles size of the nanosuspension is usually less than one micron with an average particle size ranging between 200 and $600 \mathrm{~nm}$ 31,46 .

\section{5) Super Critical Fluid (SCF) process:}

Supercritical fluid process is another novel solubilisation process. In which supercritical fluids whose temperature and pressure are greater than its critical temperature (Tc) and critical pressure (Tp), allowing it to assure the properties of both a liquid and gas. At near- critical temperature SCF, are highly compressible allowing moderate changes in pressure to greatly alter the density and mass. ${ }^{38}$ Once the drug particles are solubilized within the SCF (usually carbon dioxide). They may recrystallize at greatly reduced particle sizes. The SCF process allows micronisation of drug particle within narrow range of particle size, often to submicron level ${ }^{47}$.

\section{6) Inclusion complex formation-based technique:}

Among all the solubility enhancement technique, inclusion complex formation technique has been employed more precisely to improve the aqueous solubility, dissolution rate, and bioavailability of poorly water soluble drugs. Inclusion complex are formed by the insertion of the nonpolar molecules or the nonpolar region of one molecule (known as guest) into the cavity of another molecule or group of molecules (known as host) ${ }^{48}$ Various technological adapted to prepare the inclusion complexes of poorly water soluble drugs are.

\section{Kneading method}

$>$ Lyophilization / freeze drying technique

$>$ Microwave Irradiation method.

\section{7) Hydrotrophy:}

Hydrotrophy is a solubilisation process, whereby addition of a large amount of second solute, the hydrotropic agent result in an increase in the aqueous solubility of first solute. Hydrotropic agent are ionic organic salts, consist of alkali metal salt of various organic acids 49.

\section{Partition Coefficient}

A measurement of drugs lipophilicity and an indication of its ability to cross cell membranes is the oil/water partition coefficient in system such as octanol/water and chloroform/water. The partition coefficient is defined as the ratio of un-ionized drug distributed between the aqueous phase at equilibrium organic and.

$$
\mathbf{P} \frac{\mathbf{o}}{\mathbf{w}}=\left[\frac{\text { C oil }}{\mathbf{C} \text { water }}\right] \text { equilibrium }
$$

A sample of the drug is shaken with a mixture of octanol and water and its concentration in each layer IS determined ${ }^{39}$. 


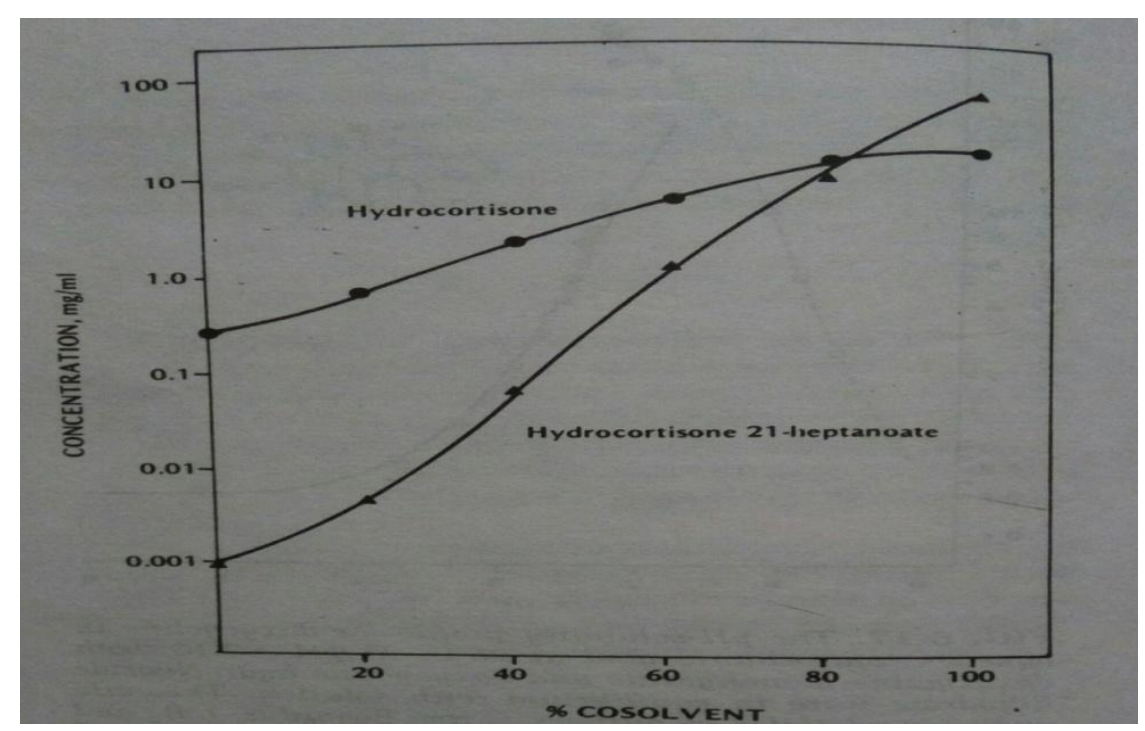

Fig.10: solubility of hydrocortisone and hydrocortisome 21-heptanoate in propylene glycol-water mixtures. (From Lachman Leon, Lieberman Herbert A. and Kanig Joseph L. "The theory and pharmaceutical of industrial pharmacy" third edition, page no. 188) ${ }^{2}$

\section{METHODS}

1) A double beam shimadzu -1800 UV-visible spectrophotometer, with spectral bandwidth of $2 \mathrm{~nm}$. Wavelength accuracy $0.5 \mathrm{~nm}$ and a pair of 1$\mathrm{cm}$ match quartz cells was used to measure absorbance of the resulting solution. Chemical which are used in the analysis are. N-octanol, salicylic acid and distilled water 16 .

2) Abraham solvation parameter model ${ }^{20}$.

The Abraham general solvation model is one of the more useful approaches for the analysis and predication of the adsorption, distribution and toxicological properties of potential drug candidates. The method relies on two linear free energy relationship one for transfer processes occurring with condensed phase.

$$
\mathrm{SP}=\mathrm{c}+\mathrm{e} \cdot \mathrm{E}+\mathrm{S} \cdot \mathrm{S}+\mathrm{a} \cdot \mathrm{A}+\mathrm{b} \cdot \mathrm{B}+\mathrm{v} \cdot \mathrm{V} .
$$

And one for process involving gas to condensed phase transfer.

$$
\mathrm{SP}=\mathrm{C}+\mathrm{e} \cdot \mathrm{E}+\mathrm{s} \cdot \mathrm{S}+\mathrm{a} \cdot \mathrm{A}+\mathrm{b} \cdot \mathrm{B}+1 . \mathrm{L} .
$$

Where, $\mathrm{E}$ and $\mathrm{S}$ refer to the excess molar refraction and bipolarity/polarization descriptor of the solute and $\mathrm{A}$ and $\mathrm{B}$ are measure of solute hydrogen bond activity and basicity, $\mathrm{V}$ is the McGowan volume and the $\mathrm{V}$ and $\mathrm{L}$, are both the measurement of solute size and also determine the solute-solvent interaction.

\section{DISSOLUTION}

Dissolution of a drug particle is controlled by several physicochemical properties, including chemical form, crystal habit, particle size, solubility surface area, and wetting properties. The dissolution rate of drug substance in which surface area is constant during dissolution is described by the modified NoyesWhiting equation.

$$
\frac{d c}{d t}=\frac{D A}{h V}(C s-C)
$$

Where, $\mathrm{D}$ is the diffusion coefficient, $\mathrm{h}$ is the thickness of the diffusion layer at the solid liquid interface. , A is the surface area of drug exposed to dissolution media, $\mathrm{v}$ is the volume of media, $\mathrm{Cs}$ is the concentration of a saturated solution of the solute in the dissolution medium at the experimental temp. And $\mathrm{C}$ is the drug in solution at time $\mathrm{t}^{2}$.

Dissolution experiments with drug suspension are further complicated by changing surface, area changing surface crystal morphology and interstitial wetting. However, dissolution profiles with excess drug can be used to characterize metastable polymorphs or solvates.

Several factors that must be considered in design of dissolution test.

- Factor relating to dissolution apparatus.

- Factor relating to dissolution fluid

- Process parameter.

Table 3: Types of apparatus used in dissolution

\begin{tabular}{|l|l|}
\hline USP Apparatus & Name \\
\hline Apparatus 1 & Rotating basket \\
\hline Apparatus 2 & Rotating paddle \\
\hline Apparatus 3 & Reciprocating cylinder \\
\hline Apparatus 4 & Flow through cell \\
\hline Apparatus 5 & Paddle overdisc \\
\hline Apparatus 6 & Cylinder \\
\hline Apparatus 7 & Reciprocating disc \\
\hline
\end{tabular}




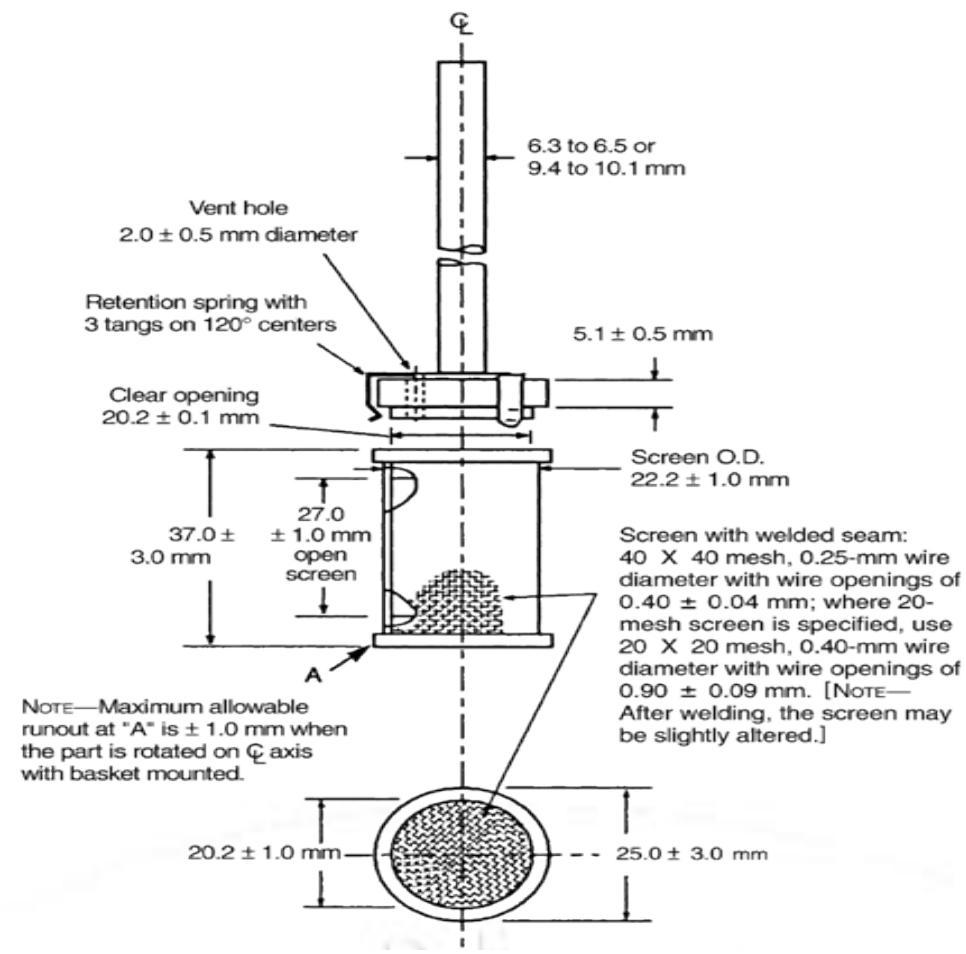

Figure 11: Two basket attachment designs: On the left is the O-ring design and on the right is the three-pronged USP Apparatus 1 design.

\section{STABILITY ANALYSIS}

Preformulation stability studies are usually the first quantitative assessment of chemical stability of a new drug. These studies include both solution and solid state experiments under condition typical for the handling formulation, storage, and administration of a drug candidate. The section focuses on the evaluation of chemical stability during preformulation research. During drug development several bulk lots are produces, reflecting scale- up and process improvements in yield, purity and possible crystability ${ }^{50}$. Upon completion of the initial stability tests one or more challenge model indicating stability may emerge that may be useful for limited testing on future bulk lots or formulation. Should a particularly difficult instability problem arise during drug development then an in-depth elucidation of the decay mechanism may suggest a stabilization approach or underscore the futility of the stabilization effort. ${ }^{51}$

\section{1) Stability in toxicology formulation:}

Since toxicology studies typically commence early in drug development, it is often advisable to evaluate sample of the toxicology preparations for stability and potential homogeneity problems. Usually a drug feed or by oral gavage of an aqueous vehicle ${ }^{52}$. Water, vitamins , minerals (metal ions) enzyme and a multitude of functional group are present in feed, which can severely reduce the shelf- life of a drug enzyme activity and moisture level typically decrease with time while feed composition varies with in consumer ${ }^{2}$.

Since enzyme activity and mobility of absorbed water vary substantially with temperature it is recommended that storage temperature typically of the toxicology laboratory be used for this stability study. Solution and suspension toxicological preparation should be checked for ease of man ufacture and the various temperatures in addition to chemical stability the suspension should be subjected to an occasional shaking to check dispersability. When analyzing the suspension data. Drug solubility at the same temp, and $\mathrm{pH}$ may suggest that only drug in solution is undergoing decomposition

\section{2) Solution Stability}

The primary objective of this phase of preformulation research is identification of condition necessary to form a stable solution.

- $\mathrm{pH}$

- temperature

- light

- oxygen

- co-solvent

- ionic strength

- Aqueous Solution for inj. PH 3 containing ironotecan $\mathrm{HCl}$, phosphate buffer and WFI was stably prepared by dissolving camptothecins without resorting to heating in the course of production.

- Solution stability investigation usually commences with probing experiments to confirm decay at the extremes of $\mathrm{PH}$ and temp ${ }^{54}$.

- Since most solution pharmaceuticals are intended for parenteral routes of administration. This initial $\mathrm{pH}$ rate study should that is compatible with physiological media.

- Co-solvent may be needed to achieve drug concentration that is necessary for analytic sensitivity or to produce a defined initial condition ${ }^{55}$. 
- Chitosan hydrogel can change reversibly well at diff. $\mathrm{pH}$ and ionic strength of solution.

- If the result of this result solution stability studies dictate the compounds as sufficiently stable liquid formulation can be developed ${ }^{56}$.

- Once the stability solution is prepared aliquots are placed in flint glass ampoules, flame sealed to prevent evaporation. Some of these solution samples should be subjected to a light stability test, which includes protective packaging in amber and yellow green glass containers.

- Given that the potential for oxidation is initially unknown some of the solution samples should be subjected to further testing.

1) With an excessive headspace of oxygen.

2) With a headspace of an invert gas such as helium or nitrogen.

3) With an inorganic antioxidant such as sodium metabisulfite.

4) With an organic antioxidant such as butylated hydroxytoulene - BHT $^{.57}$

\section{3) SOLID STATE STABILITY}

The primary objectives of this investigation are identification of stable storage condition for drug in the solid state and identification of compatible excipients for a formulation. Contrary to the earlier solution stability profile, these solid state studies may be severely affected by changes in purity and crystallinity ${ }^{58}$. In general, solid state reacts are much slower and more difficult to interpret than solution states react. Owing to reduced no. of molecular contacts between drug and excipients molecules and to the occurrence of multiple reacts ${ }^{59}$.

Solids state stability studies by-

1) Polymorphic change detected by IR spectroscopy and DSC.

2) Surface discoloration by diffuse reflecting equipment to determine the solid state stability profile of a new compound weight sample are placed in open screw cap vials and are exposed directly to a variety of emp. Humidity and light intensity up to 12 week. After that samples analyzed by HPLC.

\section{REFERENCES}

[1] Vilegave K, Gali V, "Preformulation Studies of Pharmaceutical New Drug Molecule and Products; An Overview".2013; 1(3): 2321-3647.

[2] Lachman L, Lieberman Herbert A. and Kanig Joseph L. "The Theory and Pharmaceutical of Industrial Pharmacy". Varghese publishing house, third edition, 171-196.

[3] Gopinath R., Naidu R.A.S., "Pharmaceutical Reformulation Studies-Current Review" International Journal of Pharmaceutical and Biological Archives, 2011; 2(5):13911400.

[4] Sahitya G., Krishna moorthy B., Muthukumaran M., "Importance of Preformulation Studies in Designing Formulations for Sustained Release Dosage Form", ISSN-975$766 X$.

[5] Bemis A, murcko, M.A. "Designing libraries with CNS activity". J Med. Chem., 1999; 42: 4942-51.

[6] Lathiya T, Akhilesh D., Prabhakara. P, Kamath JV "Preformulation Studies of Controlled/Sustained Release
Table 4: sample scheme for determining the bulk stability profile. ${ }^{2}$

\begin{tabular}{|lll|}
\hline & \multicolumn{2}{c|}{ Storage condition } \\
\hline Refrigerator & - & $5^{\circ} \mathrm{C}$ \\
\hline Room temperature & - & $25^{\circ} \mathrm{C}$ \\
\hline Cold & - & $2-8^{\circ} \mathrm{C}$ \\
\hline Cool & - & $8-25^{\circ} \mathrm{C}$ \\
\hline Warm & - & $30-40^{\circ} \mathrm{C}$ \\
\hline Excessive Heat & - & above $40^{\circ} \mathrm{C}$ \\
\hline Freezer & - & -20 to $-10^{\circ} \mathrm{C}$ \\
\hline
\end{tabular}

\section{Techniques for solid states stabilty studies}

- Solid state NMR spectroscopy (SSNMR).

- Power X-rays diffraction (PXRD).

- Fourier transforms IR (FTIR).

- Raman spectroscopy

- Differential scanning Calorimetry (DSC).

Thermo gravimetric analysis (TGA).

Dynamic vapor sorption (DSV) ${ }^{2}$

\section{CONCLUSION}

Preformulation studies have a significant part to play in anticipating formulation problems and identifying logical path in both liquid and solid dosage from technology. The need for adequate drug solubility cannot be emphasized. The most appropriate salt for development, Stabilities studies in solution will indicate the feasibility of parenteral or other liquid dosage form and can identify methods of stabilization. In parallel solid-state stability by DSC, TLC and HPLC in the presence of tablet and capsule excipient will indicate the most acceptable vehicles for solid dosage form.

By comparing the physicochemical properties of each drug candidate with in a therapeutic group, the preformulation scientist can assist the synthetic chemist to identify the optimum molecule, provide the biologist with suitable vehicles to elicit pharmacological response and advise the bulk chemist about the appropriate particle size and morphology for subsequent processing.

Formulation: An Overview". ISRJP, 2012; 3(5): ISSN 22308407.

[7] Walter J, Jr Weber, Chin Yu-Ping, "Determination of Partition Coefficient And Aqueous Solubility by Reverse Phase Chromatography-1", WAT Res., 1986; 20(11): 1422-1442.

[8] Qin-Wei Tong, "Pharmaceutical Preformulation:Integrated Drug Product Development Process". University of Utah. July 2006.

[9] Keseru G.M., Molnar L. And Greiner I. “A Neural Network Based Virtual High Throughput Screening Test for the Prediction of CNS Activity". Comb. Chem. High Throughput Screen, 2000; 3: 535-40.

[10] Gibson Mark, "Pharmaceutical Guide from Candidate Drug Selection To Commercial Dosage Form", 21-88.

[11] Pathare B, Tambe V, Patel V, "A Review on Various Analytical Methods Used In Determination of Dissociation Constant", International Journal of Pharmacy and Pharmaceutical Science, 2014; 6(8). 
[12] Nicklaus M.C., Milne G.W. and Zaharevitz D., "Chem-X and Cambridge: Comparison of Computer Generated Chemical Structures With X-Ray Crystallographic Data". J Chem. Inf. Compute. Sci., 1993; 33: 639-46.

[13] Marjamaki Marko, Keskinen Jorma, "Technologies for Measuring Paticulates", 248-256.

[14] Carr R.L. "evaluating flow properties of solid" Chem.Eng., 1965; 72: 163-168

[15] Sadowski J. And Kubinyi H. "A Scoring Scheme for Discriminating Between Drugs and Nondrugs". J Med. Chem., 1998; 41: 3325-3329.

[16] Mitchell T. 2006. Personal communication: Cambridge, UK.

[17] Paul K, "Measuring Particle Size Using Modern Laser Diffraction Techniques", Chem-Europe.Com,UK, WR14 1*2

[18] Sanghai B, Aggarwal G, HariKumar SL, Solid self microemulsifying drug deliviry system: a review, Journal of Drug Delivery and Therapeutics. 2013; 3 (3):168-174

[19] Weissing volkmar, pettinger K Tacy, and Murdock Nicole, "Nanopharmaceuticals Products on the Market". Internation Journal of Nanomedicine.

[20] Savjani K T., Gajjar A K., Savjani J K., "Drug Solubility: Importance And Enhancement Technique", ISRN Pharm., 2012; 195727.

[21] Gibson Mark, "Pharmaceutical Preformulation and Formulation," second edition, 188-246.

[22] Gupta M, Patel G, Nimesh S, Madhulika K. "Enhancement of Dissolution Rate of Ibuprofen By Preparing Solid Dispersion Using Different Methods". Int J Pharm and Pharm Sci, 2011; 3(3): 204-06

[23] Rutkowska Ewelina, Pajak Karolina \& Jozwiak "Kryzsztof. Lipophilicity- Methods of Determination and Its Role In Medical Chemistry". Aata Polniae Pharmaceutical Drug Research, 2013; 70(1): 3-18.

[24] SourceURL:http://chemwiki.ucdavis.edu/Physical_Chemistry/ Acids_and_Bases/Solubilty/Common_Ion_Effect

[25] Patel N, "Development and Characterization of Ternary Solid Dispersion Granules of Poorly Water Soluble Drugs: Diflunisal And Mefenamic Acid". Thesis and Dissertations. (2011) Paper 672

[26] Manallack David T, "The Pka Determination of Drug Discovery, Perspective Medicinal Chemistry”. 2007; 1: 25-38.

[27] Bulk Density and Tapped density of powders, document QAS/11. 450 March 2012.

[28] Babic Sandra, Horvath J.M Alka, Pavlovic Mtavdzic Dragana, Macan-Kastelan Marija, "Determination of Pka Values of Active Pharmaceutical Ingredients, Trends In Analytical Chemistry". 2007; 26(11).

[29] Naji SM, Yusrida D, Kok KP, “Aerodynamic Characterization of Marketed Inhaler Dosage Forms: High Performance Liquid Chromatography Assay Method for the Determination Buclesonide". 2010; 4(12): 878-884.

[30] Reijega jetse, Hoof van Arno, Loon van Antonie, Teunissen Bram, "Development of Methods of Determination of Pka Values, Analytical Chemistry Insights". 2013; 8: 53-71.

[31] Lumay G., Baschini F., Traina K., Bontempi S., Remy J.C., "Powder Technology", Measuring the flowing properties of powders and grains”. 2012; 224: 19-27.

[32] Partition and Distribution coefficients, RSC Advancing the chemical science, Reckitt Benckiser.

[33] Singh SP, Kushwah V, Rathore P, Jain P, Jaiswal S. "Determination of Partition Coefficient of Salicylic Acid between N-Octanol and Distilled Water". 3 (2): 2145-2150.

[34] Chawla G, Gupta P, Thilagavathi R., "Characterization of Solid-State Forms Of Celecoxib". European Journal of Pharmaceutical Sciences, 2003; 20: 305-317.

[35] Fairhurst David, Weiner Bruce, "A Guide To Determination of Particle Size- Making An Effective And Reliable
Measurement: Brookhaven Instruments". A Nova Instrument Company.

[36] Patel Niraja, 'Development and Characterization of Ternary Solid Dispersion Granules of Poorly Water Soluble Drugs: Diflunisal and Mefenamic Acid". 2011; Thesis and dis.

[37] Bajaj Sanjay, Sakhuja Neha, "Stability testing of pharmaceutical products". Journal of Applied Pharmaceutical Science, 2012; 02(03): 129-138.

[38] Leo Albert, Hansch Corwin and Elkine David, "Partition coefficient and their uses". 1971; 71

[39] Larsson Jesper, "Methods For Measurement Of Solubility And Dissolution Rate Of Sparingly Soluble Drugs". 2010.

[40] Horiba scientific, "A Guidebook to Particle Size Analysis

[41] Estime Nicolas, Teychene Sebastein, Autret Jean-Marie, "Influence of $\mathrm{pH}$, Temperature and Impurities on the Solubility of an Active Pharmaceutical Ingredient". API, DOI: 1542-6580.2099.

[42] Shah DP, Patel B, Shah C, Nanosuspension technology: A innovative slant for drug delivery system and permeability enhancer for poorly water soluble drugs, Journal of Drug Delivery and Therapeutics, 2015; 5(1):10-23.

[43] Gruner Klaus-Dieter, "Principle of Non-Contact Temperature Measurement".

[44] Takacs Krisztina, "Solubility-Ph Profile Dugs. Experience and Surprise in Logs Measurement".

[45] Nagendra kumar D., Ganesh KG, Shardor A, Kulkarni P, "Enhancing Dissolution Rate of Naproxen Using Modern Technique". 4(5): 929-939.

[46] Gopinath R., Naidu R.A.S., 'Pharmaceutical Preformulation Studies-Current Review”. 2001; 2(5): 1391-1400.

[47] Niazi Sarfaraz K., "Handbook of Preformulation: Chemical, Biological, and Botanical Drugs RS”. 2006; 199. F67N53.

[48] Vyas J, Patel J, Jain D. "Preparation and Characterization of Solid Dispersion of Modafinil for Improvement of Dissolution Profile". Int J Pharm and Pharmaceutical Sci, 2012; 14(5): 348-352.

[49] Dalvi PB, Gerange AB, Ingale PR, Solid dispersion: strategy to enhance solubility, Journal of Drug Delivery and Therapeutics. 2015; 5(2):20-28.

[50] Bromberg L. "Cross Linked Polyethylene Glycol Networks as Reservoirs For Protein Delivery". J Apply Poly Sci , 1996; 59: 459-466.

[51] Verma PRP, Iyer SS. “Transdermal Delivery of Propranolol Using Mixedgrades of Eudragit: Design And In Vitro And In Vivo Evaluation". Drug Dev. Ind Pharm, 2000; 26: 471-476.

[52] Martin, A., Swarbrick.J, and Cammarata, "A.Physical Pharmacy: Phisical Chemical Principles in the Pharmaceutical Sciences" $3^{\text {rd }}$ ed. Lea and Febiger, Philadelphia, 1983.

[53] Bemis, G.W. and Murcko, M.A. "Properties of known drugs. 2. Side chains". J Med. Chem., 1999; 42: 5095-5099.

[54] Ajay A., Walters W.P. and Murcko M.A. "Can We Learn To Distinguish Between "Drug-Like" And "Nondrug-Like" Molecules" J Med. Chem., 1999; 41: 3314-3324.

[55] Comer J. and Tam K. "Lipophilicity Profile Les. Pharmacokinetic Optimization in Drug Research: Biological, Physicochemical and Computational Strategies". Wiley: Zurich. 2001; 275-304.

[56] Clark, D.E. and Pickett, S.D. "Computational Methods for the Prediction of 'Drug-Likeness". Drug Discov. Today, 2000; 5: 49-58.

[57] Clark, D.E. "Computational Prediction Of Blood-Brain Barrier Permeation. Annual Reports In Medicinal Chemistry". Elsevier San Diego, 2005; 403-15.

[58] Wells, J.I "Pharmaceutical Preformulation". Ells Hoowood Ltd. London, 1998; 25.

[59] WDI the World Drug Index is available from Derwent Informatin, London, U.K. www.derwent.com. 